\title{
An index to prioritize the preventive maintenance of medical equipment
}

\author{
L. Angelica Hernández-López ${ }^{1}$ - Ana B. Pimentel-Aguilar ${ }^{2}$ • Martha R. Ortiz-Posadas ${ }^{1}$
}

Received: 14 December 2018 / Accepted: 22 August 2019 / Published online: 26 August 2019

(C) IUPESM and Springer-Verlag GmbH Germany, part of Springer Nature 2019

\begin{abstract}
We propose an index to prioritize preventive maintenance for medical equipment. Our index considers seven variables: type of equipment, equipment function, maintenance requirements, calibration, equipment age, equipment location, and equipment hazards. We developed a mathematical model using these variables, and its result is interpreted as an index of equipment maintenance priority. The numerical output of the index was classified into three categories: high, medium, and low priority. We proposed our index model to technical staff at the Department of Biomedical Engineering of the National Institute of Respiratory Diseases in Mexico as a protocol for scheduling appropriate preventive maintenance for medical equipment during the year. The index was tested in a sample of 16 different medical equipment. Our model provides a guide to define the priority and the number of preventive maintenance routines required for medical equipment per year.
\end{abstract}

Keywords Preventive maintenance prioritization $\cdot$ Index to prioritize $\cdot$ Management of medical equipment

\section{Introduction}

Health Technology Management (HTM) refers to actions carried out by health professionals to provide appropriate, safe, and effective technologies to solve a problem, integrating knowledge on engineering, logistics, planning, and resource management [1]. Preventive maintenance is a part of HTM, and its goal is to prolong the useful life of a device and prevent damage. Preventive maintenance is usually scheduled at defined intervals and includes specific tasks, such as lubrication, cleaning, or replacing parts that commonly wear out or have a short life cycle. Similarly, preventive maintenance is usually performed by the manufacturer, who also sets the maintenance procedures and intervals for each machine. However, user organizations can also adjust these intervals according to the conditions of their local environment [2]. Since organizations have the ability to determine maintenance schedules for their

Martha R. Ortiz-Posadas

posa@xanum.uam.mx

1 Electrical Engineering Department, Universidad Autonoma Metropolitana-Iztapalapa, Av. San Rafael Atlixco No. 186, Col. Vicentina, Deleg. Iztapalapa, C. P. 09340 Mexico City, Mexico

2 Biomedical Engineering Department, National Institute of Respiratory Diseases, Mexico City, Mexico own equipment, we propose an index to prioritize preventive maintenance of medical equipment. We tested the new index at the Department of Biomedical Engineering (DBE) of the National Institute of Respiratory Diseases (INER, for its acronym in Spanish) in Mexico. The index was applied in 16 different types of equipment located in different medical service departments. We believe that a maintenance program based on our index model could help extend the useful life of medical equipment and minimize its operational costs. Namely, our index model can identify and select the machines that must be included in an organization's preventive maintenance program to guarantee equipment funcionality in disease diagnosis, treatment, and rehabilitation and patient monitoring.

\section{Methodology}

\subsection{Variables}

We reviewed two medical equipment assessment models to define the variables to be included in our model. The first model was proposed by the World Health Organization (WHO) [3], and considers four variables: equipment function, the physical risk associated with the clinical application, maintenance requirements, and problem background. The second 
model was proposed by Gullikson [4], and evaluates the static and dynamic risks. Static risk considers equipment function and physical risk, whereas dynamic risk takes into account maintenance requirements and the weighted risk points. In both cases, these variables have a qualitative domain, which is used by INER's DBE technical staff to evaluate medical equipment. In this work we adapted the two aforementioned models and developed a mathematical model to map the qualitative domain to a numerical value within the interval $[0,1]$ to obtain a quantitative domain. We defined the importance of each variable in our model and assigned a weighting factor taking into consideration the experience of DBE's technical staff.

\subsection{Mathematical model}

We developed a mathematical model that incorporates the selected variables and their weighting factor. This model resulted in an index, which provides the priority of the preventive maintenance of the medical equipment evaluated. The numerical output of our model was mapped into three categories that define maintenance priority as low, medium, or high. In addition to the priority, our index determines the annual number of preventive maintenance interventions required by an specific medical equipment.

\subsection{Testing the index}

We used our model to assess 16 different medical equipment according to variable Type of Equipment (see Table 2). We randomly chose two machine per equipment type.

\section{Results}

\subsection{Variables}

We defined seven variables $\left(\mathrm{x}_{\mathrm{i}}\right)$ and their relevance factor $\left(\rho_{\mathrm{i}}\right)$. These variables have a value within the interval $[0,10]$, where 10 is associated to the highest importance and 0 the least importance (see Table 1). Note that variable Type of

Table 1 Variables $\left(\mathrm{x}_{\mathrm{i}}\right)$ and relevance factor $\left(\rho_{\mathrm{i}}\right)$ for evaluating medical equipment

\begin{tabular}{llr}
\hline $\mathrm{x}_{\mathrm{i}}$ & Variable name & $\rho_{\mathrm{i}}$ \\
\hline $\mathrm{x}_{1}$ & Type of equipment & 10 \\
$\mathrm{x}_{2}$ & Equipment function & 8 \\
$\mathrm{x}_{3}$ & Maintenance requirements & 7 \\
$\mathrm{x}_{4}$ & Calibration & 7 \\
$\mathrm{x}_{5}$ & Equipment age & 6 \\
$\mathrm{x}_{6}$ & Equipment hazards & 5 \\
$\mathrm{x}_{7}$ & Equipment location & 4 \\
Total & & 47 \\
\hline
\end{tabular}

Equipment has the highest priority, whereas variable Equipment Location has the lowest priority. On the other hand, variables Maintenace Requirements and Calibration have the same priority, since they are interrelated.

For each variable, we defined its respective qualitative $(\mathrm{Ci})$ and quantitative $\left(\mathrm{M}_{\mathrm{i}}\right)$ domains (see Table 2). Note that most of the variables $\left(\mathrm{x}_{\mathrm{i}}\right)$ have values in $\mathrm{M}_{\mathrm{i}}$ within the interval $[1,10]$, with the exception of the variable $\mathrm{x}_{1}=$ Type of Equipment, which can take values within $\mathrm{M}_{1}=[1,15]$. This is because it was important to emphasize the relevance and at the same time, the difference in the equipment type. On the other hand, variable $\mathrm{x}_{4}=$ Calibration can take Boolean values, i.e. $\mathrm{M}_{4}=[0,1]$, since it only has two options (yes / no). It is important to note that the result of the index was normalized within the interval $[0,1]$. This allows better data handling and helped us group the equipment and determine priority more easily.

\subsection{Mathematical model}

The mathematical model of our index incorporates all the variables, along with their weighting factor, as described below.

Let IPMEM be the Index to Prioritize Medical Equipment Maintenance. Hence, it can be defined by expression 1 as follows:

IPMEM $=\frac{\sum_{i=1}^{n} \rho_{i} x_{i}}{N}$

where $\mathrm{x}_{\mathrm{i}}$, is the variable to evaluate, and $\rho_{\mathrm{i}}$ is the relevance factor of each variable, $i=\{1, \ldots, 7\}$.

The result of IPMEM was confined to the the interval $[0,1]$ by a normalization factor $(\mathrm{N})$. To calculate $\mathrm{N}$, the maximum admissible value in the domain $\left(\mathrm{M}_{\mathrm{i}}\right)$ of each variable $\mathrm{x}_{\mathrm{i}}$ was multiplied by its corresponding relevance factor $\left(\rho_{\mathrm{i}}\right)$, as shown in expression 2:

$N=\sum_{i=1}^{7} \rho_{i} M_{i m \mathrm{a}^{\prime} x}$

Substituting the corresponding values in the expression 2 , we obtain the value of $\mathrm{N}$ as follows:

$$
\begin{aligned}
& N=\rho_{1}\left(M_{1 m a^{\prime} x}\right)+\rho_{2}\left(M_{2 m a^{\prime} x}\right)+\rho_{3}\left(M_{3 m a^{\prime} x}\right)+\rho_{4}\left(M_{4 m a^{\prime} x}\right) \\
& \quad+\rho_{5}\left(M_{5 m a^{\prime} x}\right)+\rho_{6}\left(M_{6 m a^{\prime} x}\right)+\rho_{7}\left(M_{7 m a^{\prime} x}\right) \\
& N=10(15)+8(10)+7(10)+7(1)+6(10)+5(5)+4(10) \\
& N=150+80+70+7+60+40+25=432
\end{aligned}
$$

Therefore, IPMEM is defined by the expression 3 as follows:

IPMEM $=\frac{\sum_{i=1}^{7} \rho_{i} x_{i}}{432}$ 
Table 2 Qualitative (Ci) and quantitative (Mi) domains of medical equipment assessment variables

\begin{tabular}{|c|c|c|}
\hline $\mathrm{x}_{\mathrm{i}}$ & $\mathrm{C}_{\mathrm{i}}$ & $\mathrm{M}_{\mathrm{i}}$ \\
\hline \multirow[t]{9}{*}{ Type of equipment } & Life support & 15 \\
\hline & Surgical and intensive care & 14 \\
\hline & Surgical sterilization & 13 \\
\hline & Monitoring of physiological variables, intensive care and surgery & 10 \\
\hline & Laboratory analysis & 8 \\
\hline & Treatment and physiotherapy & 7 \\
\hline & Laboratory accessories & 6 \\
\hline & Other equipment related with patient & 4 \\
\hline & Computer equipment & 2 \\
\hline \multirow[t]{4}{*}{ Equipment function } & Diagnostic & 10 \\
\hline & Therapeutic & 8 \\
\hline & Analytical & 6 \\
\hline & Other & 2 \\
\hline \multirow[t]{3}{*}{ Maintenance requirements } & Important & 10 \\
\hline & Usual & 5 \\
\hline & Minimum & 1 \\
\hline \multirow[t]{2}{*}{ Calibration } & Required & 1 \\
\hline & Not required & 0 \\
\hline \multirow[t]{7}{*}{ Equipment age } & 5 years or less & 1 \\
\hline & 5 to 10 years & 3 \\
\hline & 10 to 15 years & 5 \\
\hline & 15 to 20 years & 7 \\
\hline & 20 to 25 years & 8 \\
\hline & 25 to 30 years & 9 \\
\hline & 30 years or more & 10 \\
\hline \multirow[t]{19}{*}{ Equipment location } & Respiratory intensive care & 10 \\
\hline & Anesthesia service & 10 \\
\hline & Surgery, recovery and CEyE & 10 \\
\hline & Respiratory emergency unit & 10 \\
\hline & Imaging & 9 \\
\hline & Clinical hospitalization services & 8 \\
\hline & Respiratory therapy & 8 \\
\hline & Physiology respiratory & 8 \\
\hline & Hemodynamics & 8 \\
\hline & Bronchoscopy and endoscopy & 8 \\
\hline & Pulmonary rehabilitation & 7 \\
\hline & External consult & 7 \\
\hline & Blood bank & 7 \\
\hline & Clinic laboratory & 6 \\
\hline & Pathological anatomy & 6 \\
\hline & Asthma clinic & 5 \\
\hline & Respiratory sleep disorder clinic & 5 \\
\hline & Stomatology & 4 \\
\hline & Allergy and immunology clinic & 4 \\
\hline \multirow[t]{5}{*}{ Equipment hazards } & Patient or operator death & 5 \\
\hline & Patient/operator physical and emotional loss & 4 \\
\hline & Partial damage to the patient/operator & 3 \\
\hline & No apparent damage to the patient/operator & 2 \\
\hline & No significant risks & 1 \\
\hline
\end{tabular}


To interpret IPMEM results, we defined a qualitative scale with three levels of maintenance priority: low, medium, and high. These categories indicate the number of maintenance interventions required in a given medical equipment (see Table 3).

\subsection{Testing IPMEM}

We tested IPMEM among 16 different medical, thus assessing our model's functionality with respect to a range of equipment technical and functional characteristics. The 16 machines were included in the following eight equipment types: ventilator (V), autoclave (A), microscope (M), electrosurgical unit (E), electrocardiograph (Ecg), blood plasma extractor (Bpe), magnetic stirrer (Ms), surgery microscope $(\mathrm{S} \mu)$, nerve stimulator $(\mathrm{N})$, oxygen concentrator $(\mathrm{Oc})$, bed $(\mathrm{B})$, laryngoscope $(\mathrm{L})$ and oximeter $(\mathrm{O})$.

Assessing a ventilator To illustrate IPMEM's application, we discuss the results obtained after assessing one of the ventilators. The corresponding qualitative and quantitative domains are shown in Table 4.

The quantitative values $\left(\mathrm{M}_{\mathrm{i}}\right)$ and the relevance factor $\left(\rho_{\mathrm{i}}\right)$ of each variable were substituted in the expression (3),

$$
\begin{aligned}
\text { IPMEM }_{V 1} & =\frac{\sum_{i=1}^{7} \rho_{i} x_{i}}{432} \\
& =\frac{\rho_{1}\left(x_{1}\right)+\rho_{2}\left(x_{2}\right)+\rho_{3}\left(x_{3}\right)+\rho_{4}\left(x_{4}\right)+\rho_{5}\left(x_{5}\right)+\rho_{6}\left(x_{6}\right)+\rho_{7}\left(x_{7}\right)}{432} \\
\text { IPMEM }_{V 1} & =\frac{10(15)+8(8)+7(5)+7(1)+6(10)+5(5)+4(10)}{432}=0.88
\end{aligned}
$$

As shown in Table 3, the obtained index value indicates that $\mathrm{V}_{1}$ has high priority maintenance and requires at least three annual preventive maintenance routines. The high priority is because it is a life support medical equipment and it has the maximum value (15) for the variable $\mathrm{x}_{1}$ - Type of Equipment- (see Table 2). Also, the ventilator is 59 years old and can be found in the anesthesia service unit, one of the most important medical services at INER's DBE. As a result, variable Equipment Location was assigned the maximum score (10) (see Table 2). The following section discusses the results of the remaining medical equipment.

Table 3 Intervals for maintenance priority

\begin{tabular}{lll}
\hline Interval & Priority & Interpretation \\
\hline$[0-0.39]$ & Low & One maintenance intervention yearly \\
{$[0.4-0.69]$} & Medium & Two maintenance intervention yearly \\
{$[0.7-1]$} & High & At less three maintenance intervention yearly \\
\hline
\end{tabular}

Table 4 Description of ventilator $V_{1}$ in terms of the qualitative $\left(C_{i}\right)$ and quantitative $\left(\mathrm{M}_{\mathrm{i}}\right)$ domains of the seven variables $\left(\mathrm{x}_{\mathrm{i}}\right)$

\begin{tabular}{lll}
\hline $\mathrm{x}_{\mathrm{i}}$ & $\mathrm{C}_{\mathrm{i}}$ & $\mathrm{M}_{\mathrm{i}}$ \\
\hline Type of equipment & Life support & 15 \\
Equipment function & Therapeutic & 8 \\
Maintenance requirements & Usual & 5 \\
Calibration & Required & 1 \\
Equipment age & 30 years or more & 10 \\
Equipment location & Anesthesia service & 10 \\
Equipment hazards & Patient or operator death & 5 \\
\hline
\end{tabular}

\section{Discussion}

Table 5 summarizes the evaluation results, as well as the priority obtained for the preventive maintenance interventions. Regarding to $\mathrm{V}_{1}$ and $\mathrm{V}_{2}$, we obtained in both cases a high priority. Note that their description is similar except for variables Equipment Age $\left(\mathrm{x}_{5}\right)$ and Equipment Location $\left(\mathrm{x}_{7}\right)$, because $V_{1}$ is 59 years old and can be found in the respiratory intensive care service whereas $\mathrm{V}_{2}$ is 1 year old and can be found in the allergy and immunology clinic. The priority result is pre-dominate by the variables with higher weight: Type of Equipment $\left(\mathrm{x}_{1}\right)$, Equipment Function $\left(\mathrm{x}_{2}\right)$ and Maintenance Requirements $\left(x_{3}\right)$. For this reason, our index model determines that the two pieces of equipment requires at least three preventive maintenance interventions yearly. About $A_{1}$ and $\mathrm{A}_{2}$, we obtained a high and a medium priority respectively. The difference is due to the Equipment Age $\left(\mathrm{x}_{5}\right): \mathrm{A}_{1}$ is 20 years old while $A_{2}$ is 13 . Our index determined that $A_{1}$ requires at

Table 5 IPMEM results

\begin{tabular}{llllllllll}
\hline Equipment & $\mathrm{x}_{1}$ & $\mathrm{x}_{2}$ & $\mathrm{x}_{3}$ & $\mathrm{x}_{4}$ & $\mathrm{x}_{5}$ & $\mathrm{x}_{6}$ & $\mathrm{x}_{7}$ & IPMEM & Priority \\
\hline $\mathrm{V}_{1}$ & 15 & 8 & 10 & 1 & 10 & 5 & 10 & 0.88 & High \\
$\mathrm{V}_{2}$ & 15 & 8 & 10 & 1 & 1 & 5 & 4 & 0.75 & High \\
$\mathrm{A}_{1}$ & 13 & 2 & 10 & 1 & 7 & 3 & 10 & 0.74 & High \\
$\mathrm{A}_{2}$ & 13 & 2 & 10 & 1 & 1 & 3 & 10 & 0.68 & Medium \\
$\mathrm{S} \mu$ & 14 & 8 & 5 & 0 & 5 & 3 & 7 & 0.66 & Medium \\
$\mathrm{E}$ & 14 & 8 & 5 & 1 & 9 & 4 & 10 & 0.74 & High \\
$\mathrm{O}$ & 10 & 10 & 5 & 0 & 8 & 2 & 8 & 0.63 & Medium \\
$\mathrm{Ecg}$ & 10 & 10 & 5 & 0 & 1 & 2 & 8 & 0.53 & Medium \\
$\mathrm{M}$ & 8 & 6 & 5 & 0 & 5 & 2 & 6 & 0.47 & Medium \\
$\mathrm{Bpe}$ & 8 & 6 & 5 & 0 & 8 & 2 & 7 & 0.44 & Medium \\
$\mathrm{Ms}$ & 6 & 2 & 5 & 0 & 7 & 1 & 6 & 0.37 & Low \\
$\mathrm{Ms}$ & 6 & 2 & 5 & 0 & 10 & 1 & 6 & 0.41 & Medium \\
$\mathrm{N}$ & 7 & 8 & 10 & 1 & 7 & 3 & 7 & 0.62 & Medium \\
$\mathrm{Oc}$ & 7 & 8 & 5 & 1 & 5 & 3 & 8 & 0.51 & Medium \\
$\mathrm{B}$ & 4 & 2 & 5 & 0 & 5 & 2 & 10 & 0.30 & Low \\
$\mathrm{L}$ & 4 & 2 & 5 & 0 & 8 & 2 & 8 & 0.34 & Low \\
\hline
\end{tabular}


least three maintenance interventions yearly whereas $\mathrm{A}_{2}$ requires just two. In relation to $\mathrm{E}$ and $\mathrm{S} \mu$, we obtained a high and medium priority respectively. They have differences in four variables: Calibration $\left(\mathrm{x}_{4}\right)$, E require calibration whereas $\mathrm{S} \mu$ does not; Equipment Age $\left(\mathrm{x}_{5}\right)$, E is 27 years old whereas $\mathrm{S} \mu$ is 10 years old; Equipment Hazards $\left(\mathrm{x}_{6}\right)$, E can cause patient/ operator physical and emotional loss whereas $\mathrm{S} \mu$ can cause partial damage to the patient/operator, and Equipment Location $\left(\mathrm{x}_{7}\right), \mathrm{E}$ can be found in the respiratory emergency unit whereas $\mathrm{S} \mu$ can be found in the external consult service. Finally, our index determined that $\mathrm{E}$ requires at least three maintenance interventions yearly whereas $\mathrm{S} \mu$ require two. As regards to $\mathrm{Ecg}$ and $\mathrm{O}$ we obtained a medium prioritty. Both are physiological variable monitoring $\left(\mathrm{x}_{1}=\right.$ Type of Equipment) and are used to diagnose diseases $\left(\mathrm{x}_{2}=\right.$ Equipment Function). They require usual maintenance interventions ( $\mathrm{x}_{3}=$ Maintenance Requirements), they can cause no apparent damage to the patient/operator $\left(\mathrm{x}_{6}=\right.$ Equipment Hazards), and both are located in hospitalization services ( $x_{7}=$ Equipment Location), one in oncological pneumology, and the other in the intersticial lung disease. In conclusion, our index determined these equipment require two preventive maintenance interventions yearly. About $\mathrm{M}$ and Bpe we obtained a medium priority. Their description coincides except for the Equipment Age $\left(\mathrm{x}_{5}\right)$ and Equipment Location $\left(\mathrm{x}_{7}\right)$, because $\mathrm{M}$ is 14 years old and can be found in the pathological anatomy service, whereas Bpe is 22 years old and can be found in the blood bank service. Our index determines that the two pieces of medical equipment requires two maintenance interventions yearly. As regards to $\mathrm{Ms}_{1}$ and $\mathrm{Ms}_{2}$, we obtained a low and medium priority respectively. Their descriptions does not coincides in the Equipment Age $\left(\mathrm{x}_{5}\right)$ because $\mathrm{Ms}_{1}$ is 40 years old whereas $\mathrm{Ms}_{2}$ is 16 , and this fact influence the priority result. Our index determined that $\mathrm{Ms}_{1}$ requires one maintenance intervention yearly whereas $\mathrm{Ms}_{2}$ requires just two. In relation to $\mathrm{N}$ and $\mathrm{Oc}$, we obtained a medium priority. Their description does not coincides in three variables: Maintenance Requirements $\left(\mathrm{x}_{3}\right)$, Equipment Age $\left(\mathrm{x}_{5}\right)$ and Equipment Location $\left(\mathrm{x}_{7}\right)$, but this differences does not influence the priority result because they have medium relevance. Therefore, our index determined that both medical equipment require one maintenance intervention yearly. Finally for B and L we obtained in both cases a low priority. Note that their description differs in the Equipment Age $\left(\mathrm{x}_{5}\right)$ and Equipment Location $\left(\mathrm{x}_{7}\right)$, because B is 13 years old and can be found in the respiratory emergency unit, whereas L is 22 years old and can be found in hemodynamics. The differences in their description do not change their priority, so that our index determined that these equipment requires one preventive maintenance intervention yearly.

\section{Conclusions}

IPMEM provides a new method to assess medical equipment and define whether it should be incorporated in a preventive maintenance program. To this end, IPMEM requires information regarding type of equipment, function, maintenance requirements, hazards, age, and medical service. We tested the index in a sample of 16 medical equipment of eight types, and thus different characteristics. We found that two variables $\mathrm{x}_{5}=$ Equipment Age, $x_{7}=$ Equipment Location, have an important influence on the results of the priority of medical equipment in terms of preventive maintenance interventions. Similarly, the test results indicate that our index allows defining the priority and the number of preventive maintenance interventions required yearly per piece of medical equipment. This information positively contributes to INER's DBE preventive maintenance program. However, IPMEM can be also used along the entire organization. In this sense, its results could be an auxiliary criterion that would support annual preventive maintenance programs, not only at INER, but also in any other medical Institute.

Acknowledgments The authors of this paper want to acknowledge to the technical staff of the Biomedical Engineering Department of the National Institute of Respiratory Diseases from Mexico, for their priceless support for developing this work.

\section{Compliance with ethical standards}

Conflict of interest The authors declare that they have no conflict of interest.

Ethical approval This article does not contain any studies with human participants or animals performed by any of the authors.

\section{References}

1. Sarlinga M. Medical technology management. German Hospital, Argentina. 2008. http://auditoriamedicahoy.com. Accessed July 2009.

2. World Health Organization. Maintenace related definitions. In: Medical equipment maintenance programme overview. WHO Medical device technical series. Switzerland, World Health Organization; 2011. p. 12-13. http://apps.who.int/medicinedocs/ documents/s21566en/s21566en.pdf. Accessed February 2018.

3. World Health Organization. Risk-based biomedical equipment management programme. In: Medical equipment maintenance programme overview. WHO Medical device technical series. Switzerland, World Health Organization; 2011. p. 44-47. http:// apps.who.int/medicinedocs/documents/s21566en/s21566en.pdf. Accessed February 2018.

4. Gullikson ML. In: Yadin D, Maltzahn WW, Neuman MR, Bronzino YJD, editors. Risk factors, safety, and management of medical equipment. Boca Raton: CRC Press; 2005. p. 32-46.

Publisher's note Springer Nature remains neutral with regard to jurisdictional claims in published maps and institutional affiliations. 